Session 2342

\title{
The Role of Masters degrees in Technology \& Business to promote CPD for Engineering Professionals
}

\author{
B R Dickson \\ Department of Chemical \& Process Engineering, \\ University of Strathclyde, \\ Glasgow, Scotland, UK.
}

\begin{abstract}
There is an increasing realisation that the MBA approach to career development is not the most relevant form of education \& training for engineers. During the mid 1990's, the UK's Engineering and Physical Science Research Council (EPSRC) funded over 20 Masters programmes that had at their heart:

- Promotion of subject-specific advanced engineering topics

- A parallel approach to teach management practice to an engineering audience

- The creation of a management role for industrial representatives in academic programmes
\end{abstract}

These Integrated Graduate Development Schemes (IGDS) cover a wide range of industries aerospace, chemical, material science and manufacturing engineering being some of the many represented in the programme. They all endeavour to meet the need for employment-based parttime learning within the context of continuing professional development, providing core and advanced engineering knowledge \& skills and encouraging a multi-disciplinary approach to the learning process. IGDS courses provide a technology-based version of an MBA and features a strong multi-disciplinary theme that integrates advanced technologies, management and business (with a strong emphasis on the process of innovation) and IT strategy.

The paper will look at some of the reasons for the development of these programmes, drawing in particular on the model from the University of Strathclyde's department of Chemical \& Process Engineering and parallel programmes in the IGDS Process Industries Sector group. The University has pioneered several postgraduate distance-learning courses for industry-based students that are unique in the UK and are attracting interest on a world-wide basis. The design and development of the course was undertaken with a wide range of partners including industry, Professional Institutions and other Universities. The course delivery involves new methods of teaching, learning and communications that range from text-based to internet-based. There is a strong emphasis on employment-based project work.

The paper will also cover:

- The key features of course and curriculum development and the role of partnerships

- The most effective methods of teaching, learning and communication

"Proceedings of the 2002 American Society for Engineering Education Annual Conference \& Exposition Copyright (C) 2002, American Society for Engineering Education” 
- The most effective use of work-based projects

- The methods of achieving team-work with widely dispersed students

- Case Studies illustrating the diversity of students' background, learning experiences and outcomes from the courses

- Conclusions and wider implications for engineering education

- Make comparisons with similar programmes which provide Masters level CPD

\section{Introduction}

In 1971, J. Sterling Livingston, then Professor of Business Administration at Harvard Business School report the "Myth of the well-educated Manager" ${ }^{[1]}$.

"Managers are not taught in formal education programmes what they need to know to build successful careers in management. Most management graduates prefer staff positions in headquarters to line positions."

Livingston also reported that

"A few MBA holders continue to rise dramatically, the career growth of most of them levels off just at the time men who are destined for top management typically show their greatest rate of advancement".

Some 30 years later the UK higher educational establishment has produced 100,000 MBA graduates, most of whom would suggest that they wanted to

- Be better managers

- Improve their career prospects

If those objectives are true and Professor Livingston's assertion that most would become "staffers" is also true, then over the period, UK companies should not be dominated by MBA executives, only a few would reach the top.

Research into nearly 9000 individuals from companies listed in the London Stock Exchange provides an illuminating answer to this issue of "Reaching for the top".

It would hardly be surprising to see that $\sim 43 \%$ of company directors hold only an accountancy qualification and only a small group of $10.5 \%$ are MBA graduates. The dominance of accountants in UK industry is so complete that only 61 (6.5\% of all MBAs) accountants added an MBA, to their qualifications. 


\begin{tabular}{|l|c|c|}
\hline \multicolumn{1}{|c|}{ Qualification } & No. & \% \\
\hline Accountancy & 3830 & $42.7 \%$ \\
\hline $\begin{array}{l}\text { Accountancy/MSc } \\
\text { BSc\&BEng }\end{array}$ & 54 & $0.6 \%$ \\
\hline Law & 269 & $3.0 \%$ \\
\hline MBA & 758 & $8.5 \%$ \\
\hline MBA/PhD MSC BSc\&BEng & 126 & $1.4 \%$ \\
\hline MBA/Acc & 61 & $0.7 \%$ \\
\hline PhD & 376 & $4.2 \%$ \\
\hline MSc & 159 & $1.8 \%$ \\
\hline BSc\&BEng & 981 & $10.9 \%$ \\
\hline Other & 2353 & $26.2 \%$ \\
\hline Total & 8967 & $100.0 \%$ \\
\hline
\end{tabular}

Table 1: FTSE Company Director Qualifications ${ }^{[2]}$

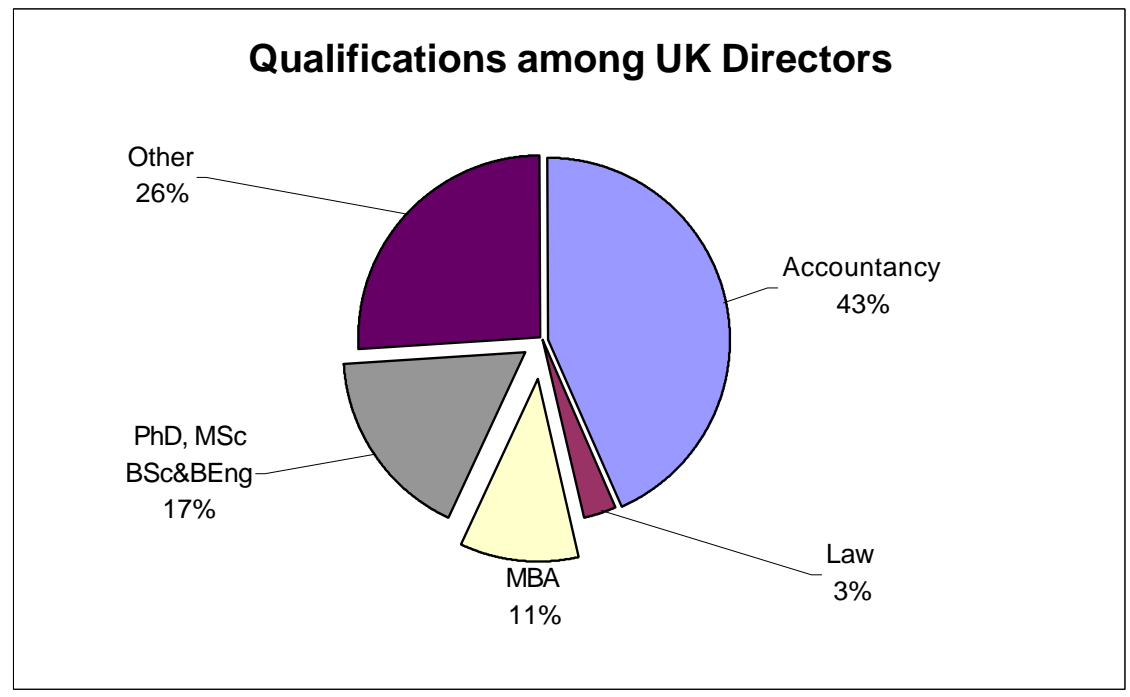

Fig1: Qualifications amongst UK Directors of FTSE Companies 2001

However the interesting element of this analysis is the higher number of "Technical" graduates $(\sim 17 \%)$ holding a $\mathrm{PhD}, \mathrm{MSc}, \mathrm{BEng}$ or $\mathrm{BSc}$, who are at this level. Technical graduates only represent $13.3 \%$ of all MBAs, the greatest majority $(\sim 80 \%)$ are non-technical graduates by first qualification.

It would appear therefore that since only $9.9 \%$ of non-accountant UK Directors hold MBAs, this seems to partially support Professor Livingston's view i.e. apart from graduates in Arts and Social Sciences, MBAs are not a particularly successful way to the top.

"Proceedings of the 2002 American Society for Engineering Education Annual Conference \& Exposition Copyright (C) 2002, American Society for Engineering Education” 


\section{IGDS Programmes}

It would be convenient to assume Professor Livingston's view led some 20 years later to the UK Higher Education Funding body, the Engineering and Science Research Council (EPSRC) to commence funding the development of Integrated Graduate Development Schemes (IGDS).

However at a time EPSRC was working closely with the Department of Trade and Industry (DTI) to find way of meeting "industries needs" - i.e. to produce better technical managers who can run and build businesses and the IGDS programme began.

IGDS is a part-time, modular, Master's level training programme run as a partnership between businesses and universities, offering a wide range of highly adaptable, industrially relevant courses. These courses are structured so that they are easily tailored to individual needs and thus enhance the contribution of the individual delegates to their company.

The overriding objective is to enable delegates to perform their jobs better by continuing their professional development; so the courses are designed not only to impart relevant technical knowledge but also the management skills necessary to make the most of that knowledge. There are now some 45 separate programmes and over 300 companies have supported IGDS, covering a huge range of industries, all with a common objective of:

- Promotion of subject-specific advanced engineering topics

- A parallel approach to teach management practice to an engineering audience

- The creation of a management role for industrial representatives in academic programmes

They all endeavour to meet the need for employment-based part-time learning within the context of continuing professional development, providing core and advanced engineering knowledge $\&$ skills and encouraging a multi-disciplinary approach to the learning process.

It is interesting to note however that the format of workbased learning that all these courses take mirrors again Professor Livingston's comments from 1971

"Formal management education programmes typically emphasises the development of problem solving and decision-making skills, for instance but give little attention to ..... skills ..... to carry out successful operating plans once they are made"

"Lectures, case discussions are of limited value .......finding them (problem solving) in real business situations is the only method that will make a manager skillful by identifying the right thing to do"

In fact, perhaps Prof Livingston's views were not that original since,

"During the first decade of the $20^{\text {th }}$ century, Dr Alex C. Humphreys, the President of the Stevens Institute of Technology, the privately endowed college of engineering and science described above, was also a successful practicing engineer of high standing. He gave an address on 'Business training for the engineer' in which he began with an axiom: "Selfevident should be the truth of the proposition that the engineer ought to be a man of business,

"Proceedings of the 2002 American Society for Engineering Education Annual Conference \& Exposition Copyright (C) 2002, American Society for Engineering Education” 
or at least informed of, and prepared to conform to, business conditions and business methods. Businessmen bankers, and manufacturers not infrequently refuse their confidence to engineers and experts as a class, because, under trial, some individuals have demonstrated their incapacity to meet business conditions; from the standpoint of the man of business their reports, advice, conclusions have required interpretation and readjustment or amendment. The man, so far somewhat exceptional, who is able to bring to the service of clients or associates a sound technical training and the ability to meet business conditions, proves by his comparative success the material value of this dual capacity. For the sake of the profession and the country at large it is important that this broader capacity should no longer be exceptional" [3]

Even today views of "the modern manager" is not all that different with the arrival of the "Tshaped manager" from Hansen (Harvard Business School) and Oetinger (Boston Consultants Group).

"We call the approach T-shaped management. It relies on a new kind of executive, one who breaks out of the traditional corporate hierarchy to share knowledge freely across the organisation (the horizontal part of the "T") while remaining fiercely committed to individual business unit performance (the vertical part). The successful T-shaped manager must learn to live with, and ultimately thrive within, the tension created by this dual responsibility. Although this tension is most acute for heads of business units, any T-shaped manager with operating unit obligations must wrestle with it." [4]

\section{A Case Study: MSc in Process Technology \& Management}

\subsection{Background}

Commencing in 1997 at the University of Strathclyde, Glasgow, the programme comprises three elements: Process Technology, Management and Business, Information Technology, the approximate weightings being 50\%, 30\% and 20\% respectively. The full MSc programme requires 12 'taught' modules and a substantial Project (rated at 3 modules equivalent). Partial completion is recognised at Diploma level, and single modules and/or groups of modules will be available to meet individual CPD requirements.

The normal duration for the full MSc is three years, with delegates typically undertaking 5 modules per annum, but flexibility in the duration is possible in order to accommodate the career needs of the delegates and the requirements of their employers

\subsection{Programme Content}

The Process Technology modules address two major priority areas for the process industries:

(i) The design, optimisation, control and operation of processes which are cleaner, safer and more economic;

(ii) A deeper understanding of principles in complex areas, for example multi-phase solid/liquid/gas mixtures, which can be applied to the improvement of existing processes and the development of new processes.

"Proceedings of the 2002 American Society for Engineering Education Annual Conference \& Exposition Copyright (C) 2002, American Society for Engineering Education” 
The Management and Business modules address the concepts and techniques relevant to the planning, organisation and control of businesses:

(i) Operations and project management

(ii) Accounting \& finance

(iii) Marketing

(iv) Human resource management.

The IT modules focus on strategic and operational issues relevant to the process industries:

(i) The development and impact of Information Systems Strategies;

(ii) The operational implications of database systems, networking and communications.

The "taught" modules develop generic knowledge and skills, and include a wide range of group work to assist the delegates in technology transfer and in identifying applications to specific processes and to different 'types' of process (batch/continuous, large/small scale, fluid/particle, chemical/biochemical).

The Project, which is designed to integrate the elements of the programme, will have a strong technology content, and is totally work-based to enable the delegates to apply their enhanced knowledge and skills to the benefit of their employer.

This overall structure provides:

(i) a cohesive and common core for all delegates which include a significant amount of advanced process technology;

(ii) sufficient electives to accommodate a range of delegate requirements, from those with a strong interest in technology (studying 8 technology modules) to those with a strong interest in management and business (studying 6 management modules).

\subsection{Programme Objectives}

Right from the outset, all IGDS programmes are required to report to a Management Committee, which must have industrialists and not academics in the majority, and this leads to an emphasis that course material needs to be

- Industry relevant

- Demonstrate payback

- Develop the individual

An appropriate way to achieve these objectives is the use of Action Learning which Margerison $^{[5]}$ defines as

"that Managers can

1. learn from experience

"Proceedings of the 2002 American Society for Engineering Education Annual Conference \& Exposition Copyright $\bigodot^{\circ}$ 2002, American Society for Engineering Education” 
2. share experiences with others

3. have those colleagues criticise and advise

4. take that advice and implement it

5. review with those colleagues the action taken and the lessons that are learned"

This is supported by Dale's ${ }^{[6]}$ view on learning;

"Involvement of appropriate others in appropriate ways can have a number of predictable outcomes

- Group working avoids tram-line thinking

- Individual assumptions are questioned by concerned others

- Debate stimulates the creation of new ideas

- Group members help each other stand back from the problem to reframe it

- The available experience, knowledge, and revalidated as a result of group discussion, challenge and debate

- Group members can mentor and coach each other, and providing 'moral' support and encouragement

- People are essentially social creatures and generally function better when working with others in conducive settings"

So in practice, modules in:

\section{Safety and Environment \\ Process Design* \\ Manufacturing Technology \\ Projects \& Operations Management*}

\author{
General \& Strategic Management* \\ Information Systems Strategy* \\ Databases \\ Managing Software Development*
}

All have a work based and often group based activity (*) as the assessment method. This results in reports from students that they have achieve successful implementation of their learning in their work place based on course material.

A significant number of these modules use electronic conferencing to allow groups to work together in a geographical dispersed format, sharing experiences, reviewing working practices, and agreeing common final group reports. Not only does this extend the group learning outside the formal tutorials at the University, it assists in eliminating "the loneliness of the long-distance learner" and build cohort camaraderie.

\subsection{Programme Outcomes}

The programme has been described as a Technical MBA, since it mixes advanced technical subjects with business management. Its particular success is a final Major Project that requires students to link the components of Technology, Business Management \& IT. 
Our experience to date confirms that the output can have substantial impact on the student's company:

- A "conventional" effluent treatment analysis, found previously un-recognised toxic hazards and the need for site management to review the resource implications of altering production processes.

- A review of potential new product applications will probably save substantial costs by not taking what would have been a wrong direction.

- That the "conventional" design reduced throughput \& quality as it was duplicated on a world-wide basis, since "convention" was taken as "standard \& best", rather than what is was - "at best average".

These examples perhaps don't seem startling but the issues had never been addressed until the student ask the Line Manager for a project topic and got the response:

"well, we have been needing to look at this for some time"

(and never got round to it)

The experiences of students are varied and sometimes unusual across individual modules too;

GS: Wrote a report on improving customer service from material in Manufacturing Technology, his MD liked what he read, implemented it across all the company sites and now Graham is in charge of Plant in Holland - The drawback- being sent to a monastery ...for 2 weeks intensive training in Dutch.

PR: Had his annual review "I am about to finish my MSc - what next?" and he is now Plant Manager in Alaska. More importantly, with access to a "green card" and a permanent post in Houston.

C D: Needed to write a report on his organisation's Safety Systems as the main assignment for Safety and Environment and his recommendations are now Standard Operating Practice- and he got paid a bonus for achieving this.

Not all the students have such dramatic events, but since a large part of the course has this work based assignment approach, recent research amongst the 90+ students in the programme, suggest that $4 / 5$ modules will have an immediate impact on the student's company. This more than justifies the cost of paying for the course, it's a double payback really for students - assistance with career development and demonstrating their worth to the organisation at the same time.

More importantly the work-based project gives the student a major opportunity to confirm Livingston's view of :

“(Problem Solving) in real business situations makes a manager skillful ......"

"Proceedings of the 2002 American Society for Engineering Education Annual Conference \& Exposition Copyright () 2002, American Society for Engineering Education” 


\section{Moving From Anecdotal Evidence To A Research Project}

What has been reported so far is the result of the author working with one course group of students and relying on individual reports from students. If the IGDS concept, i.e. a programme leading to an award in Masters in Technology \& Management, is of value and has been successful it should be possible to chart and measure that success.

In trying to evaluate the effectiveness of theses industrial based Masters Training Programmes, such as IGDS, it is of interest to course funders \& providers to review the effectiveness as a whole of these forms of programmes. Since they were based around a principle of CPD and industrial relevance, what interests us most are the deliverables at the end of the course.

As such, it is "impact" that we would like to measure rather than "did you enjoy the lecture?"

To assess impact, Kirkpatrick's ${ }^{[7]}$ four levels of evaluation of the training program is considered to be relevant, i.e. consisting of
(1) Reaction,
(2) Learning,
(3) Behaviour, \&
(4) Impact or Results.

1. Reaction is a measure of how well the participant liked the training program with respect to its content and delivery. Reacting to a training program with happiness does not guarantee that learning has taken place.

2. Learning is the next level of measure of effectiveness of the training program, but this learning change does not always produce behavioural change in the participants.

3. Behaviour as the next level of effectiveness of the program should be geared toward determining change in behaviour of participants. This change can be measured in terms of changes in decision making and leadership styles for example. This behavioural change is attributable to the program.

4. Impact or Results is the final level of measure of effectiveness of the training program that demonstrates that, after the dissipation of effect, the residual change is permanent. This measurement is generally carried out as a post study activity. This is the impact of a manager's training on his behavior and the effect of that changed behavior in his organisation.

An effective management development program evaluation and review technique must be strategically designed to be all-inclusive with respect to assessing reaction, learning, behaviour and the results accruing due to the programme.

In considering this Evaluation Strategy, we would normally measure the impact that the training had on the delegates' company. However, since current economic conditions the UK Process Industries Sector are so fluid, it was felt that to be of value, the evaluation of impact should be "in the company" and "to the individuals career".

"Proceedings of the 2002 American Society for Engineering Education Annual Conference \& Exposition Copyright () 2002, American Society for Engineering Education” 
To achieve this, a pilot study is now underway in the "Process Industries Sector" of the IGDS programmes using the questionnaire shown in Table 2 . Since the group of programmes only began to graduate delegates from 1997, the population is small and sufficiently coherent to test out the questionnaire and allow an initial analysis of the "comments" section to be viable.

\begin{tabular}{|c|c|c|c|c|}
\hline Measure & $\begin{array}{l}\text { Form of } \\
\text { Evaluation }\end{array}$ & Grading & Score & $\begin{array}{l}\text { Appropriate } \\
\text { Examples or } \\
\text { Comments }\end{array}$ \\
\hline Reaction & $\begin{array}{l}\text { Rating the form } \\
\text { of Delivery }\end{array}$ & $\begin{array}{l}\text { 1- Poor } \\
\text { 2- Adequate } \\
\text { 3- Good }\end{array}$ & & \\
\hline Learning & $\begin{array}{l}\text { Information \& } \\
\text { Skills Gained }\end{array}$ & $\begin{array}{ll}\text { 1- } & \text { None } \\
\text { 2- } & \text { Some } \\
\text { 3- } & \text { Satisfactory }\end{array}$ & & \\
\hline Behaviour & $\begin{array}{l}\text { Knowledge \& } \\
\text { Skills Transferred } \\
\text { to the workplace }\end{array}$ & $\begin{array}{ll}\text { 1- } & \text { None } \\
\text { 2- } & \text { Some } \\
\text { 3- } & \text { Satisfactory }\end{array}$ & & \\
\hline Results & $\begin{array}{l}\text { Effect on :- } \\
\text { Organisation's } \\
\text { Performance } \\
\text { Your own Career } \\
\text { Development }\end{array}$ & $\begin{array}{l}\text { 1- None } \\
\text { 2- Some } \\
\text { 3- Satisfactory } \\
\text { 1- None } \\
\text { 2- Some } \\
\text { 3- Satisfactory }\end{array}$ & & \\
\hline
\end{tabular}

Table 2: Programme Evaluation Form

What was also of interest was the possibility of comparing this evaluation technique with a small group of students that the author had taught as part of the Open University distance learning MBA programme and who had graduated at around the same time as the IGDS group.

The results at this stage are tenuous since the sample size is only 15 graduating students in each category. What does seem to be a possible outcome is that for the evaluation score "impact in companies", there is a higher score for Technology \& Management graduates than MBA graduates. The only occasion Technology \& Management students do not score this category highly, is where their company is closing or subject to some other form of structural change, which is supported by the accompanying comments. For the MBA graduates, the survey seems to suggest that the main difference in the results, is this "lack of impact" in their workplace. The "best" workplace application for MBA students comes from a move into consultancy and becoming "experts" - very much a return to Livingston's view perhaps.

"Proceedings of the 2002 American Society for Engineering Education Annual Conference \& Exposition Copyright () 2002, American Society for Engineering Education” 
Outside this category of "Effect on Organisation's Performance", there are no differences in scores.

The following charts details these initial findings:

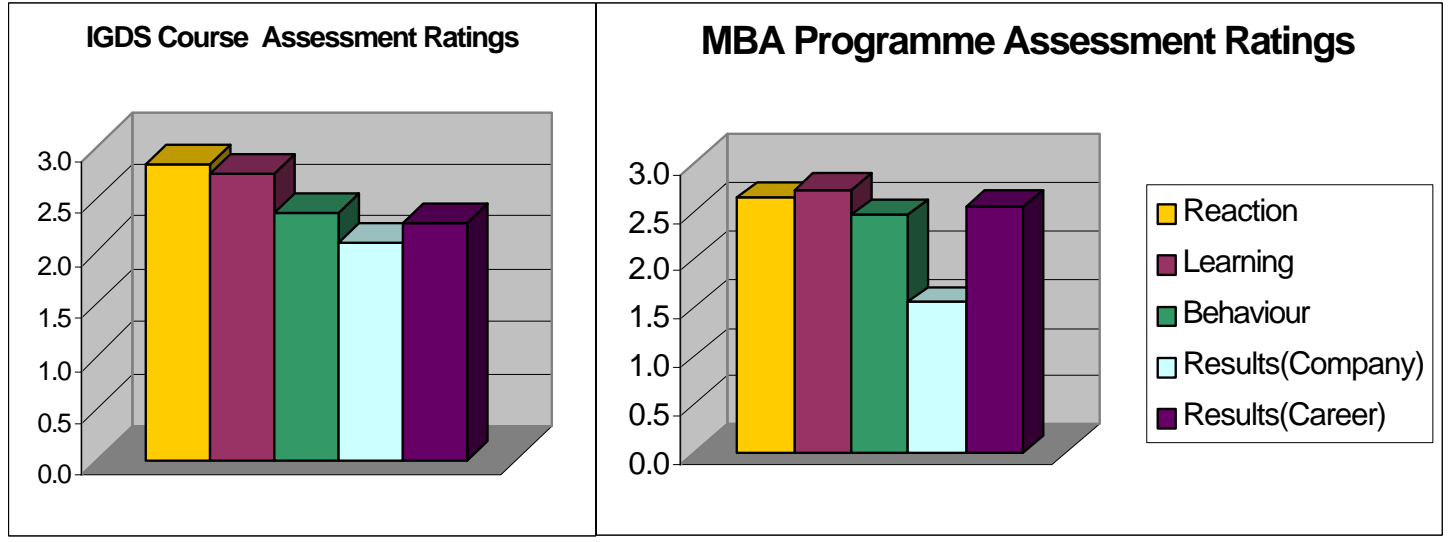

Fig3: Current Assessment Results at March 2002

Depending on the continued evaluation of this questionnaire, it intended to gain EPSRC support for a large study across all IGDS programmes and gain access to a wide MBA population to make this same comparison. In particular, in a much wider and broader survey it will be possible review age, experience and first degree/qualification with the categories set out in the Directors' survey set out at the beginning of the paper. The results may help academics, sponsors and funders develop programmes that demonstrate impact and show benefit to the overall economy as well as continue to support the individual aspirations of students to become "better managers" and "assist in their career development".

\section{Conclusion}

Historical academic publications suggests that Management Development programmes of the MBA format may not be entirely successful and based on the qualifications of the UK Company Director population of London Stock Market quoted companies, this may be true. MBA graduates are still outnumbered by Technical graduates by almost a factor of two to one amongst directors in these companies.

The UK Government and Industry's view that good technical graduates with a business training are more appropriate to the economy's needs match with the above finding and early research into the impact of "Technology and Management Programmes" appears to confirm that view. 
Perhaps then a new concept of Executive Training \& Development needs to be developed, one where technical excellence and business impact can be matched.

The IGDS Masters Programmes feature Scientists and Engineers, who want to learn about technical issues. They don't stop at the basic level - they want to understand where the role of Engineering lies in their company's business and use our courses to move their careers forward, demonstrating their worth to their organisation.

If this is to be the case, then a new Model of Learning needs to be developed as an appropriate way of describing that desire and Fig 4 could be a representation of that thought process.

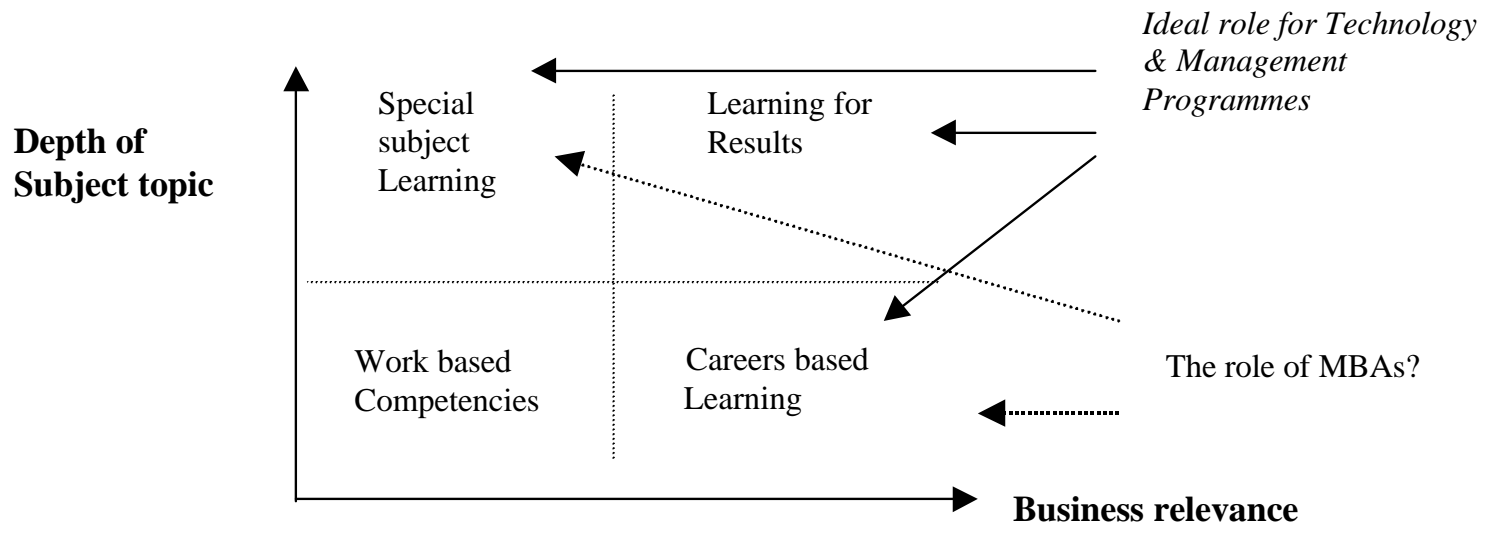

Fig 4 : A New Model of Learning

\section{References}

[1] J STERLING LIVINGSTON "Myth of the well-educated manager", HBR Jan-Feb 1971, No 71108:

[2] Source: HEMSCOTT GROUP LTD, London

[3] Taken from J.IRWIN "Early 20th Century Advance to Young American Engineers": Engineering Science and Education Journal - December 2001

Source: Addresses to engineering students (Waddell and Harrington, Consulting Engineers, Kansas City, Missouri, USA, 1911)

[4] M.T. HANSEN and B. VON OETINGER "Introducing the T-Shaped Manager" HBR March 2001

[5] C.J. MARGERISON “Action Learning and excellence in Management development” Managing Learning: Mabey and Iles: The Open University, 1994

[6] M DOLE "Learning Organisations" Managing Learning: Mabey and Iles: The Open University, 1994

[7] KIRKPATRICK D.L. "Evaluating Training Programs” The Four Levels, Berrett-Koehler, 1998

"Proceedings of the 2002 American Society for Engineering Education Annual Conference \& Exposition Copyright () 2002, American Society for Engineering Education” 